\title{
STATE-CHURCH RELATIONS AND THE RELIGIOUS SITUATION IN A PROVINCIAL TOWN IN 1997-2003 (ON THE EXAMPLE OF TOLYATTI)
}

\author{
Vadim N. Yakunin \\ Volga State Orthodox Institute, Tolyatti, Russian Federation
}

\begin{abstract}
Introduction. The goal of the article is to investigate the nature and assess the results of statechurch relations in Tolyatti after the implementation of the Federal Law "On Freedom of Conscience and Religious Associations" of September 26, 1997. Materials and Methods. In order to implement the goal of the research, we used the materials of the municipal public institution "Tolyatti Archive" (orders and resolutions of the mayor of Tolyatti), data from periodicals, memoirs of contemporaries, materials of the current archive of the Samara diocesan administration closed to the public (reports of the ruling Bishop of the Samara diocese to the Moscow Patriarchate), materials from the author's personal archive: reports of the assistant governors of Samara Oblast on religious issues reports of both secular and ecclesiastical officials on the religious situation in Samara Oblast and Tolyatti, other official and unofficial documents, many of which, due to their specificity, do not end up in Church or secular archives (correspondence between the heads of local religious organizations with Tolyatti Duma and City Hall officials; protocols of City Hall meetings on religious issues and the protocols of meetings in the religious organizations, which were conducted by the author). The research methodology includes the method of document analysis. Analysis. The construction of churches, the development of educational institutions, the opening of a monastery, guardianship and fraternities, and the publication of religious periodicals continued in 1997-2003. For Tolyatti's clergy and believers, the preparation and celebration of the $2000^{\text {th }}$ anniversary of the Nativity of Christ was an opportunity to express themselves in the media, increase the number of parishes and ask the authorities for assistance in solving various life issues including financial assistance. The Orthodox clergy also hoped to solve the problem of various religious organizations and sects functioning on the territory of Tolyatti, which they considered their canonical territory, with the help of the authorities. Results. With the celebration of the $2000^{\text {th }}$ anniversary of Christianity, Orthodox religious organizations strengthened their position in society, established a dialogue with business and government, and gained advantages over other religious organizations in all matters. It was connected with both the allocation of land for temples and their subsequent financing.
\end{abstract}

Key words: temples, cathedrals, churches, monasteries, clergy, bishops, charity.

Citation. Yakunin V.N. State-Church Relations and the Religious Situation in a Provincial Town in 1997-2003 (On the Example of Tolyatti). Vestnik Volgogradskogo gosudarstvennogo universiteta. Seriya 4. Istoriya. Regionovedenie. Mezhdunarodnye otnosheniya [Science Journal of Volgograd State University. History. Area Studies. International Relations], 2021, vol. 26, no. 4, pp. 54-65. (in Russian). DOI: https://doi.org/10.15688/ jvolsu4.2021.4.5

\section{ГОСУДАРСТВЕННО-ЦЕРКОВНЫЕ ОТНОШЕНИЯ И РЕЛИГИОЗНАЯ СИТУАЦИЯ В ПРОВИНЦИАЛЬНОМ ГОРОДЕ В 1997-2003 гГ. (НА ПРИМЕРЕ ГОРОДА ТОЛЬЯТТИ)}

\author{
Вадим Николаевич Якунин \\ Поволжский православный институт им. Святителя Алексия, митрополита Московского, \\ г. Тольятти, Российская Федерация
}


Аннотация. В статье исследуется взаимодействие религиозных организаций г. Тольятти с органами власти и управления, а также религиозная ситуация в г. Тольятти в 1997-2003 годах. Этот период интересен прежде всего началом нового этапа государственно-церковных отношений, наступившего после принятия Федерального закона от 26 сентября 1997 г. «О свободе совести и религиозных объединениях». Сделан вывод о том, что православные религиозные организации Тольятти при помощи и поддержке государства, местных органов власти по максимуму использовали преамбулу Федерального закона «О свободе совести и религиозных объединениях», где признавалась особая роль православия в истории России, в становлении и развитии ее духовности и культуры. Доказывается, что к концу рассматриваемого периода православным религиозным организациям Тольятти удалось укрепить свои позиции в обществе, наладить диалог с бизнесом и властью и получить преимущества во всех вопросах своей жизнедеятельности по сравнению с другими религиозными организациями (прямое финансирование из бюджета и выделение земельных участков в лучших районах города).

Ключевые слова: храмы, соборы, церкви, монастыри, духовенство, архиереи, благотворительность.

Цитирование. Якунин В. Н. Государственно-церковные отношения и религиозная ситуация в провинциальном городе в 1997-2003 гг. (на примере города Тольятти) // Вестник Волгоградского государственного университета. Серия 4, История. Регионоведение. Международные отношения. -2021. - Т. 26, № 4. - С. 54-65. DOI: https://doi.org/10.15688/jvolsu4.2021.4.5

Введение. В статье рассмотрено изменение государственно-церковных отношений в 1997-2003 гг. на примере г. Тольятти. Проанализировано соотношение официальной религиозной политики с конкретным ее воплощением на местах. Цель статьи - исследовать характер и оценить результаты государственно-церковных отношений в Тольятти после принятия Федерального закона от 26 сентября 1997 г. «О свободе совести и религиозных объединениях».

Хронологические рамки исследования охватывают 1997-2003 гг., так как за этот период можно проследить, как воплощалась в жизнь государственная церковная политика на местах после принятия данного закона.

Методы и материалы. Цель исследования была достигнута на основе использования материалов муниципального казенного учреждения (МКУ) «Тольяттинский архив» (распоряжения и постановления мэра г. Тольятти), данных периодической печати, воспоминаний современников, материалов закрытого для общественности текущего архива Самарского епархиального управления (отчеты правящего архиерея Самарской епархии в Московскую патриархию), материалов личного архива автора: отчетов помощников губернатора Самарской области по религиозным вопросам, отчетов чиновников как светских, так и церковных о религиозной обстановке в Самарской области и г. Тольятти, других официальных и неофициальных материалы, многие из которых в силу своей специфики не по- падают ни в церковные, ни в светские архивы (переписка руководителей местных религиозных организаций с чиновниками мэрии и Думы г. Тольятти, протоколы совещаний в мэрии по религиозным вопросам и протоколы совещаний в религиозных организациях, которые вел автор, работая в местной православной религиозной организации и в мэрии Тольятти в 1998-2001 гг.) [55].

Методология исследования включает метод анализа документов, в работе с материалами периодической печати был применен метод синхронного сопоставления с документальным материалом.

Анализ. 26 сентября 1997 г. был принят Федеральный закон «О свободе совести и религиозных объединениях». Новым было то, что в преамбуле закона признавалась особая роль православия в истории России, в становлении и развитии ее духовности и культуры. Несмотря на то что это была только преамбула закона, юридически не дающая никаких дополнительных прав, православные религиозные организации при помощи и поддержке государства постарались использовать ее в свою пользу. В ст. 9 закона признавалось необходимым для религиозных групп иметь подтверждение их существования на данной территории на протяжении не менее 15 лет, выданное органами местного самоуправления, или подтверждение о вхождении в структуру централизованной религиозной организации того же вероисповедания, выданное указанной организацией. Именно ст. 9 закона о 15-летнем цензе стала камнем 
преткновения и споров между «традиционными» и «новыми» религиозными организациями.

Рассмотрим религиозную ситуацию в Тольятти в 1997-2003 гг. и как она изменилась после принятия нового закона.

В Самарской области и г. Тольятти самой крупной по количеству приходов религиозной организацией была Русская православная церковь (далее - РПЦ). В постсоветское время увеличилось количество храмов, усилилось влияние веры и церкви на все стороны жизни россиян [49, с. 295]. В 1997 г. на территории города было зарегистрировано 9 православных приходов, 1 монастырь, 3 домовых церкви, но только 3 прихода и 1 часовня располагались в уже построенных храмах [53]. Несмотря на то что церковь активно боролась в конце советского периода за сохранение материального наследия, ощущался острый недостаток мест служения [48, с. 113, 114]. Власти выделяли приходам квартиры на первых этажах многоэтажек либо неприспособленные помещения, где совершались церковные службы. В такие приходы назначали настоятеля, который обустраивал выделенное помещение под временную церковь и одновременно руководил организацией строительства стационарного храма. В 2 больницах Тольятти были открыты молитвенные комнаты [14, л. 13]. Все храмы г. Тольятти, за исключением Благовещенского в Федоровке, были новостройками. В 1998-2003 гг. открылось еще 4 прихода и 10 молельных комнат и часовен, домовых церквей на производствах ОАО «АвтоВАЗ», в медицинских и социальных учреждениях, в Тольяттинском военно-техническом институте, Тольяттинском филиале Самарской гуманитарной академии, в доме ветеранов и исправительной колонии № 16 [17; 26; $29 ; 46 ; 54]$.

Управляющий Самарской епархией (территориально совпадала с границами Самарской области) архиепископ Самарский и Сызранский Сергий (Полеткин) старался поднять роль Церкви в общественной жизни, для этого он встречался с руководством Тольятти, руководителями тольяттинских предприятий и организаций, на которых поднимал вопросы о передаче церковным организациям зданий и строений, выделении им земельных участков, финансовой и материальной помощи при стро- ительстве новых храмов, противодействии в деятельности новых религиозных организаций, установлении сотрудничества с муниципальными органами в области духовного просвещения и социального служения $[15$, л. $2 ; 16$, л. 1-2; 27]. Того же архиерей требовал от подчиненных: в Тольятти - от благочинного Ставропольского округа (куда входили г. Тольятти и Ставропольский район) протоиерея Николая Манихина и настоятелей приходов. Приходы имели формально независимый юридический статус местной православной религиозной организации и собственный расчетный счет, но фактически, согласно Уставу РПЦ, настоятели полностью подчинялись епархии в лице ее правящего архиерея. Благочиние же ни юридического статуса, ни тем более расчетного счета не имело, при всем том именно благочинный рекомендовал правящему архиерею назначить того или иного священнослужителя в конкретный приход. В 2002 г. Ставропольское благочиние было разделено на два - Тольяттинское во главе с протоиереем Николаем Манихиным, в которое вошли все городские приходы, и Ставропольское, в которое вошли сельские приходы Ставропольского района. Это было логичное решение в свете увеличения количества приходов и активизации религиозной жизни.

Община Русской православной старообрядческой церкви организационно оформилась в Тольятти в конце 90-х гг. ХХ в., что позволило ей в начале 2000-х гг. обратиться в мэрию Тольятти с просьбой выделить землю под храм.

В 1998 г. мэрией г. Тольятти был выделен под строительство католического костела участок земли у кинотеатра «Сатурн», где установили сборную модульную церковь, изготовленную в Германии, которая была освящена 20 декабря 1998 года. В 2002 г. приходу был выделен участок земли под строительство стационарного храма [1]. В связи с празднованием 1700-летия крещения Армении в Тольятти с 2001 г. активизировалось движение за строительство первоапостольской церкви. У баптистов церковь «Благая весть» имела собственное церковное здание. Две другие баптистские церкви - «Возрождение» и «Пробуждение»-своих помещений не имели и брали их в аренду. В 2002 г. мэрией г. Тольятти 
была выделена земля под строительство баптистской церкви «Возрождение» [1]. Пятидесятнические общины были представлены такими организациями, как «Христианин», «Открытое небо», «Глобальная стратегия» и «Осанна». Все они арендовали помещения для своих собраний $[1 ; 44]$. Из протестантских организаций в Тольятти имелись по 1 общине новоапостольской церкви, духовных христиан-молокан, адвентистов седьмого дня [5; 25].

Мусульманские религиозные организации были разобщены, самой крупной из них была соборная мечеть, построенная в 1997 г. [50]. Другие объединения - «Вахдад» и «Байт-Аллах»- собственных помещений не имели, были немногочисленны. Соборная мечеть и «Вахдад» входили в состав центрального духовного управления мусульман России, а «БайтАллах» - в состав духовного управления мусульман европейской части России [1]. Эти противоречия не позволили реализовать проект строительства Джума Джами мечети в Автозаводском районе, хотя деньги для этого строительства выделялись, в том числе и из бюджета Тольятти $[42 ; 51]$.

Община иудеев находилась в стадии регистрации. Буддисты были представлены филиалом необуддийского центра Карма Кагью [4; 9].

В Тольятти в тот период времени действовали неоднозначно воспринимаемые религиоведами и общественностью общины «Богородичного центра», «свидетелей Иеговы» ${ }^{1}$, саентологов, сахаджа-йоги, кришнаитов, церкви Иисуса Христа Святых последних дней (мормоны), последователей Саи-Бабы, секты Виссариона (Церковь Последнего Завета) $[8 ; 43 ; 52]$, последователей Порфирия Иванова и других. Свидетели фиолетового пламени, гедеоновы братья не были зарегистрированы [39], что не мешало им вести свою деятельность, другие же были зарегистрированы под видом общественных организаций: сахаджа-йога, кришнаиты, дом Рерихов, саентологи (гуманитарный центр «Дианетика») $[3 ; 6 ; 8]$. Последние активно действовали и набирали своих последователей, особенно среди молодежи [3; 6].

Церковь Иисуса Христа Святых последних дней (мормоны) приобрела в 2002 г. у OОО «ГриГер» в собственность здание для проведения культовых мероприятий. Активная публичная деятельность этой организации к этому времени пошла на спад после ряда публикаций в прессе, в которых выражалась озабоченность укоренением организации в Тольятти. Протестанты, как и представители нетрадиционных для России религиозных организаций, использовали под свои собрания дома молодежи, дворцы культуры, кинотеатры, библиотеки, актовые залы учебных заведений, арендовали помещения детских садов, школ, училищ, колледжей [7]. Саентологи организовывали платные семинары, арендовали помещения в одной из школ города, а когда родители выступили против такого соседства, то переместились в стены кулинарного училища. Религиозные общины пятидесятнического направления «Открытое небо», «Христианин», «Тольяттинский христианский центр» организовали в Тольятти «Огненную конференцию» 26-28 мая 2000 г. на стадионе «Строитель» и «Фестиваль музыки и чудес» с 22 июля по 27 августа 2000 г., в ходе которого установили шатер наподобие циркового (первоначально в Автозаводском, а затем в Центральном районе), и там собирали своих последователей $[13 ; 18]$. Характерный факт, который показывает противоречивость государственной религиозной политики в те годы, - несмотря на то что мэрия Тольятти разрешила мероприятия, заместитель мэра отправил по месту регистрации пятидесятнических церквей в отдел юстиции администрации Самарской области письмо с пунктами допущенных нарушений во время проведения мероприятий организаторами фестиваля: «В представленных уставах организаторов отсутствует разрешение на осуществление оздоровительной медицинской деятельности (заживление ран, избавление от недугов). В то же время на мероприятиях фестиваля в ходе отправления культа явно просматриваются суггетивные методы воздействия на человеческую личность» [13].

Начиная с 1998 г. на страницах местной прессы появляются статьи, комментарии, прямые линии с профессиональными экспертамирелигиоведами по проблеме функционирования новых для Тольятти религиозных организаций $[6 ; 10 ; 44 ; 45]$, с 2000 г. стали публиковаться обращения православных священнослужителей с протестом против религиозной 
экспансии новых религиозных организаций, в том числе зарегистрированных под видом общественных [11]. По их мнению, было необходимо упорядочить деятельность новых религиозных организаций, которые составляли конкуренцию православным организациям [20].

25 февраля 1998 г. на совете благочиния Ставропольского округа было принято обращение к председателю Тольяттинской городской думы А.Н. Дроботову, в котором указывалось, что «нормальное существование традиционной для России Православной Церкви в действительности нарушается ничем не ограниченной деятельностью тоталитарных сект», которые «активно внедряются в образовательную систему». Совет благочиния просил «ограничить деятельность на территории г. Тольятти деструктивных и тоталитарных сект» [21; 36]. Под сектами подразумевались религиозные организации, которые были новыми для г. Тольятти.

Представители православной церкви были против проникновения на территорию Тольятти новых для города религиозных организаций, к каким они относили всех, кроме представителей ислама и евангельских христиан-баптистов. Исключение делалось лишь для римскокатолической церкви (с оговоркой, чтобы она не вела миссионерскую деятельность). Планы строительства католиками большого костела и монастыря с благотворительной столовой и медиацентром вызвали обеспокоенность у православных священнослужителей, в мае 2002 г. они обратились по этому поводу с письмом к мэру г. Тольятти, отметив, что количество тольяттинцев, исповедующих католицизм, незначительно по сравнению с размерами предполагаемого строительства [1]. В результате костел, хоть и позже, но все-таки был построен, однако без монастыря, благотворительной столовой и медиацентра.

Начиная с 90-х гг. XX в. в России стали популярны такие формы работы с населением, как прямые линии, телефоны доверия. Но только в ноябре 2002 г. в Тольятти начал реализовываться проект «Прямая линия телефона доверия», который был призван помочь в поисках ответа на вопросы в тех ситуациях, когда люди не могли оперативно обратиться за советом к православному священнику.
Характерной особенностью нового этапа государственно-церковных отношений, наступившего после принятия Федерального закона от 26 сентября 1997 г. «О свободе совести и религиозных объединениях», можно назвать активную помощь со стороны властных структур православным религиозным организациям. Она заключалась в предоставлении им лучших земельных участков для строительства храмов, помещений для совершения богослужений, выделении денежных средств как напрямую, так и опосредованно, через благотворительные фонды, в содействии в проведении юбилейных мероприятий в честь 2000 -летия христианства [22; 41], оказании помощи в организации визита в Тольятти Патриарха Московского и всея Руси Алексия II 14 октября 1999 г. [34]. В свою очередь Русская православная церковь на местах пыталась встроиться в государственную систему, в том числе и в области образования, получить все возможные преференции как крупнейшая конфессия России [33]. Это выражалось в стремлении получить доступ в систему образования Тольятти через факультативные курсы «Основы православной культуры» (далее - ОПК), организацию для учителей города, преподающих ОПК, 2-годичных катехизаторских курсов, причем финансировались эти курсы мэрией г. Тольятти [35].

Показательно стремление руководящих церковных деятелей даже во внешних атрибутах копировать поведение властной элиты города. Об этом свидетельствует, в частности, письмо благочинного Ставропольского округа протоиерея Николая Манихина в мэрию Тольятти с просьбой установить на свой автомобиль «проблесковые маячки-мигалки» [19]. В тот период времени (2000 г.) такую привилегию в Тольятти имели только начальник ГАИ УВД г. Тольятти Александр Шелудяков и президент - генеральный директор ОАО «АвтоВАЗ» Алексей Николаев.

Начиная с 2000 г. с приходом нового политического руководства в России положение религиозных организаций начинает меняться, причем без изменений и поправок в сам закон «О свободе совести и религиозных объединениях». Так, в июле 2000 г. Министерство образования РФ направило в регионы письмо с требованием воспрепятствовать проникнове- 
нию «нетрадиционных религиозных объединений в образовательные учреждения РФ» [23; 24]. В этом письме использовались такие наименования религиозных организаций, как «нетрадиционные, деструктивные религиозные объединения и организации», «секты», «сектантские общины».

Ссылаясь на это письмо, архиепископ Самарский и Сызранский Сергий обратился в августе 2000 г. к только что избранному мэру Тольятти Н.Д. Уткину с письмом, в котором заявил, что «нормальное существование традиционной для России Православной Церкви в действительности нарушается ничем неограниченной деятельностью религиозных сект. В настоящее время на территории г. Тольятти действует более 30 религиозных организаций, из них несколько откровенно тоталитарного характера, известные своим разрушающим влиянием на психику... Эти организации активно внедряются в образовательную систему, арендуют дворцы культуры и стадионы г. Тольятти для проведения своих мероприятий...» [30].

До 2002 г. власти г. Тольятти и правоохранительные органы наблюдали за происходящим в религиозной сфере, вмешиваясь, если только действия религиозной организации грозили нарушением общественной безопасности и порядка. Представители силовых структур направляли инкогнито наблюдателей на собрания последователей новых религиозных организаций, но практики запрета или воспрепятствования их деятельности со стороны органов власти не было. Попыткой решить эту проблему явилось создание в начале 1999 г. Совета по проведению государственной религиоведческой экспертизы при администрации Самарской области, состоящего из 7 специалистов-религиоведов, правоведов и государственных служащих [31]. Но он имел исключительно совещательные функции, собирался редко и нерегулярно, поэтому никак повлиять на ситуацию не мог.

В конце ноября 2002 г. в Тольятти состоялся круглый стол «Взаимодействие государства и религиозных объединений в сфере борьбы с экстремизмом». Его ведущим был министр РФ по делам национальностей В. Зорин. Он подчеркнул, что обсудить именно эту тему в Тольятти предложил лично прези- дент РФ В.В. Путин, так как государственная политика в духовной сфере нуждается в изменениях [1]. В Тольятти такие изменения произошли уже в том же году, когда мэрия отказала местной организации "Свидетели Иеговы» в выделении земельного участка под строительство «зала царств». Об этом архиепископ Самарский и Сызранский Сергий просил мэра г. Тольятти Н.Д. Уткина практически сразу же после его избрания в августе 2000 г., указывая на то обстоятельство, что «зарубежные центры поддержали и уже согласились оплатить этот проект» [30]. В том же 2002 г. общественная организация «Дианетика», под эгидой которой действовала без регистрации религиозная организациясаентологов, была ликвидирована по решению центрального районного суда Тольятти [1].

11 апреля 2003 г. в Тольятти прошел круглый стол «Взаимодействие органов власти и религиозных организаций в достижении общественного согласия и сохранении национальных и духовных традиций», в котором приняли участие представители власти, традиционных религиозных конфессий, правоохранительных структур, общественных организаций. Ведущим круглого стола был начальник отдела по религиозным вопросам и культурным правам аппарата уполномоченного по правам человека РФ М.И. Одинцов. Участники круглого стола выразили мнение о необходимости усиления роли влияния государства на ситуацию, связанную с деятельностью религиозных организаций на территории РФ [12].

Преамбула закона «О свободе совести и религиозных объединениях», признающая особую роль православия в истории России, стала основанием для подписания соглашений о сотрудничестве органов власти со структурами Русской православной церкви как в центpe, так и на местах. Подобные соглашения подписывались и с исламскими религиозными организациями.

В 2001 г. было заключено соглашение о сотрудничестве между мэрией Тольятти и Ставропольским благочинием Самарской епархии [47], в 2002 г. соглашение о взаимодействии было подписано между мэрией Тольятти, региональным духовным управлением мусульман Самарской области и религиозной организацией «Соборная мечеть» [1]. 
Значение заключенных соглашений было в том, что формализовывались отношения властей Тольятти с традиционными религиозными организациями. Так, в соглашении между мэрией Тольятти и Ставропольским благочинием предусматривалось лоббирование не только церковных интересов (содействие со стороны мэрии в подготовке и переподготовке педагогических кадров через двухлетние катехизаторские курсы при православной классической гимназии, поддержка кафедры православной педагогики, поддержка православных периодических изданий и др.), но и содействие развитию народных традиций, патриотического воспитания, этнокультурного развития [32].

В 2003 г. был создан консультационный общественный Совет по взаимодействию органов власти и религиозных организаций при Управлении по общественным, межрегиональным связям и информационно-аналитической работе мэрии г. Тольятти. То, что такой совет был создан при управлении мэрии, а не при самой мэрии, изначально снижало его значимость. В 2003-2004 гг. было проведено всего несколько заседаний этого совета, с 2005 г. заседания не проводились. В совет вошли 9 человек, из них 2 священнослужителя РПЦ, имам, 2 представителя мэрии, 3 представителя от вузов города и главный врач психоневрологического диспансера [28]. Как и общественные советы при большинстве муниципальных образований, созданные ради видимости вовлечения общественности в принятие решений, этот совет каких-то значимых решений для города не принял и не мог принять, поэтому его создание было в то время скорее данью моде, чем насущной необходимостью власти делегировать кому бы то ни было хотя бы часть своих полномочий.

Результаты. Появление новых религиозных организаций как в России в целом, так и в Тольятти в частности вызывало недовольство со стороны православного и мусульманского духовенства и верующих. Православные и мусульманские служители культа и общественность по этому поводу выступали в прессе, обращались в органы власти различного уровня, предлагали создать религиозный совет для урегулирования спорных вопросов и назначить ответственного за развитие рели- гиозной ситуации в городе чиновника, разбирающегося в проблеме [8; 40]. Представители традиционных для России конфессий видели необходимость регулирования религиозной сферы государством (в том числе и в виде определенных ограничений для новых религиозных организаций, что было отражено в ст. 9 нового закона). В Тольятти, как и в России в целом, в этом отношении взгляды православного и мусульманского духовенств совпали. Православные лидеры религиозных организаций Тольятти были не готовы к полной самостоятельности в решении даже таких внутриконфессиональных вопросов, как финансирование строительства культовых зданий.

Перед православным духовенством в Тольятти, как и во всей России, встал в те годы вопрос об усилении внебогослужебной деятельности церкви. Руководство церкви и сама жизнь требовала от них «пойти в народ»: открывать воскресные школы, детские кружки, организовывать благотворительные столовые для нищавшего населения, помогать нуждающимся, больным людям. И то и другое одновременно силами одного человека, настоятеля прихода, не всегда получалось: надо было ездить по спонсорам, изыскивать средства на строительство или реконструкцию храма, решать организационные вопросы по отводу земли, подключения к коммуникациям. В этом случае внебогослужебная деятельность могла стать формальной (для отписки вышестоящему начальству) не из-за нежелания, а просто из-за отсутствия времени ее проводить. И все же, несмотря на трудности, она проводилась настоятелями и священниками многих тольяттинских приходов.

В 1997-2003 гг. продолжалось строительство православных храмов, развитие учебных заведений с православным уклоном, издание религиозной периодики. Были открыты монастырь, благотворительные фонды, попечительства и братства.

Вместе с тем в выделении денежных средств из бюджета на храмы не было открытости, обсуждения ни в церковной среде, ни в обществе. Приходы, которые и без того имели хорошие доходы, получали дотации [37], а строящимся приходам денег не хватало, их настоятели вынуждены были ходить по предприяти- 
ям и организациям и просить финансовую помощь, вместо того чтобы развивать внебогослужебную деятельность. В тольяттинской прессе появились публикации, авторы которых задавались резонным вопросом: почему в финансировании из бюджета делается предпочтение православным храмам, ведь в Тольятти живут представители разных вероисповеданий и все они платят налоги? И если бы мэрия направила те же деньги на финансирование социальных статей бюджета (пенсии, субсидии, помощь инвалидам и сиротам), то она совершила бы не менее богоугодное дело [2].

Православные лидеры религиозных организаций Тольятти были не готовы к полному устранению государства от участия в религиозных вопросах: и в силу исторической традиции, и в условиях сложившейся ситуации проникновения в город новых религиозных организаций, в которых видели угрозу своей монополии в духовной сфере. Православное духовенство надеялось упорядочить с помощью власти проблему функционирования на территории Тольятти, которую оно считало своей канонической территорией, иных религиозных организаций, в том числе и новых для города. Местные чиновники и бизнесмены также старались использовать авторитет православной церкви для своих политических амбиций, если не напрямую, то опосредованно, через получение в торжественной обстановке наград и дальнейшее освещение награждения в прессе.

В целом необходимо признать, что духовный и личный авторитет руководителей тех или иных религиозных организаций помогал решать организационные вопросы, привлекал таких же энтузиастов и подвижников своего дела.

\section{ПРИМЕЧАНИЕ}

120 апреля 2017 г. решением Верховного суда Российской Федерации деятельность религиозной организации «Управленческий центр свидетелей Иеговы в России» и всех его региональных отделений признана экстремистской и запрещена на территории России.

\section{СПИСОК ЛИТЕРАТУРЫ}

1. Аналитическая справка по ситуации в религиозных организациях Тольятти за 2003 г. Подго- товлен сотрудником мэрии Тольятти Кутыревой Н.П. // Архив В.Н. Якунина.

2. Батулова, С. Благотворительность за чужой счет? / С. Батулова // Тольяттинское обозрение. 2000. - 29 марта. - С. 4.

3. Воронцова, Е. Я рождаюсь на земле снова и снова / Е. Воронцова // Площадь свободы. - 2000. 19 янв. - С. 3.

4. Громыко, В. Ум есть пространство. В Тольятти открыт филиал буддийского центра Карма-Кагью / В. Громыко // Площадь свободы. - 1992. 1 июля. - С. 2.

5. Гуенко, Л. Новая церковь с приветом из Цюриха / Л. Гуенко // Презент. - 1998. - 2 марта. C. $1-2$.

6. Гуревич, С. У каждого своя формула счастья / С. Гуревич // Площадь свободы. - 1998. 16 окт. - С. 3.

7. Ельникова, Е. Мормоны: Бархатный захват / Е. Ельникова // Политический ринг. - 1999. - 9 дек. C. 4 .

8. Караулов, В., священник. Секты наступают / В. Караулов // Любимый город. - 1996. - № 2. C. 3 .

9. Костин, В. Какую же «посевную» проводят у нас кришнаиты? / В. Костин // Тольятти сегодня. 1995. - 29 марта. - С. 3.

10. Лысякова, С. Шатер чудес в стране дураков / С. Лысякова // Площадь свободы. - 2000. 27 июля. - С. 4.

11. Манихин, Н. Кому Церковь не мать, тому Бог не отец / Н. Манихин // Площадь свободы. 2000. - 11 авг. - С. 4.

12. Мощенко, М. Секты в законе. Пока / М. Мощенко // Миллион. Вечерняя газета. - 2003. - Апр. (№ 7 (66)) . - C. 3.

13. Мощенко, М. Сети веры/ М. Мощенко // Миллион плюс. -2000. - Авг. (№ 80 (210)). - С. 3.

14. Отчет архиепископа Самарского и Сызранского Сергия в Московскую Патриархию за 1998 г. // Текущий архив Самарского епархиального управления. - Л. 1-25.

15. Отчет архиепископа Самарского и Сызранского Сергия в Московскую Патриархию за 1999 г. // Текущий архив Самарского епархиального управления. - Л. 1-30.

16. Отчет архиепископа Самарского и Сызранского Сергия в Московскую Патриархию за 2001 г. // Текущий архив Самарского епархиального управления. - Л. 1-35.

17. Панорама Тольятти. $-2003 .-17$ янв. - С. 1 .

18. Перовская, С. Пятидесятники «обживают» Центральный район / С. Перовская // Площадь свободы. $-2000 .-23$ авг. - С. 4.

19. Письмо благочинного Ставропольского округа протоиерея Николая Манихина в мэрию 
Тольятти заместителю мэра г. Тольятти С.А. Капорцеву от 16.03.2000 г. // Архив В.Н. Якунина.

20. Письмо благочинного Ставропольского округа Самарской епархии протоиерея Николая Манихина мэру г. Тольятти С.Ф. Жилкину от 14.05.1998 г. // Архив В.Н. Якунина.

21. Письмо благочинного Ставропольского округа Самарской епархии протоиерея Николая Манихина председателю Тольяттинской городской Думы Дроботову А.Н. № 38 от 26.02.1998 // Архив В.Н. Якунина.

22. Письмо директора департамента финансов мэрии г. Тольятти В.В. Кушнарева начальнику управления по организационным вопросам мэрии Тольятти Е.Ю. Обориной № 895 от 01.10.2001 г. // Архив В.Н. Якунина.

23. Письмо заместителя и. о. начальника главного управления образования администрации Самарской области В.А. Прудниковой № 1818 от 21.08.2000 г. // Архив В.Н. Якунина.

24. Письмо заместителя министра образования РФ Е.Е. Чепурных № 549/28-16 от 06.07.2000 г. с приложением на 4 с. «Информация о деятельности на территории России представителей нетрадиционных религиозных объединений» // Архив В.Н. Якунина.

25. Площадь свободы. - 1997. - 25 янв. - С. 1.

26. Площадь свободы. - 1999. - 26 янв. - С. 1.

27. Повестка дня встречи 22 марта 2020 г. архиепископа Самарского и Сызранского Сергия с руководством г. Тольятти, ОАО «АВТОВАЗ», предпринимателями и промышленниками Тольятти, настоятелями тольяттинских приходов // Архив В.Н. Якунина.

28. Положение о консультационном общественном совете по взаимодействию органов власти и религиозных организаций при управлении по общественным, межрегиональным связям и информационно-аналитической работе мэрии г. Тольятти. Предложения участников совета. Повестка заседания совета от 10.06.2004 г. // Архив В.Н. Якунина.

29. Постановление мэра г. Тольятти. 07.08.1998 // Архив В.Н. Якунина.

30. Проект письма Архиепископа Самарского и Сызранского Сергия мэру Тольятти Н.Д. УТкину // Архив В.Н. Якунина.

31. Проект постановления об организации Сoвета по проведению государственной религиоведческой экспертизы при администрации Самарской области // Архив В.Н. Якунина.

32. Проект соглашения о сотрудничестве между мэрией Тольятти и Ставропольским благочинием Самарской епархии // Архив В.Н. Якунина.

33. Протокол № 4 собрания Ставропольского благочиния от 16 декабря 1999 г. // Архив В.Н. Якунина.

34. Протокол встречи в мэрии Тольятти от 16.09.1999 г. // Архив В.Н. Якунина.
35. Протокол совещания рабочей группы по программе подготовки к 2000-летию Христианства // Архив В.Н. Якунина.

36. Протокол заседания Совета Благочиния Ставропольского округа от 25.02.1998 // Архив В.Н. Якунина.

37. Распоряжение мэра г. Тольятти № 274-1/p от 05.07.2001 // Муниципальное казенное учреждение «Тольяттинский архив». - Ф. Р-410. - Оп. 2. Д. 546. - Л. 42-43.

38. Распоряжение мэра г. Тольятти № 324-1/p от 01.08.2001 // Муниципальное казенное учреждение «Тольяттинский архив». - Ф. Р-410. - Оп. 2. Д. 546. - Л. 157.

39. Религиозные объединения граждан, зарегистрированные в Самарском областном отделе юстиции // Архив В.Н. Якунина.

40. Религиозный совет городу необходим. Беседа с имамом-мухтасибом Анасом Галиахметовичем Галиаскаровым // Тольятти сегодня. - 1997. 5 апр. - С. 3.

41. Решение ТГД № 738 от 16.02.2000 г. о мероприятиях, посвященных празднованию 2000-летия со дня Рождества Христова, и Приложение № 1 к нему // Архив В.Н. Якунина.

42. Русов, С. Скандал вокруг строительства мечети / С. Русов // Площадь свободы. - 1997. 15 окт. - С. 3.

43. Сафонова, Е. Дом Иеговы на стадионе «Торпедо» / Е. Сафонова // Площадь свободы. 1997. -9 авг. - С. 2 .

44. Скоренева, Е. Моего мужа увела секта / Е. Скоренева // Тольяттинское обозрение. $-1999 .-26$ июля. C.3.

45. Тарасова, О. Опасно, когда человек становится фанатиком / О. Тарасова // Площадь свободы. $-2001 .-14$ июля. - С. 2.

46. Тольяттинское обозрение. - 2002. 15 февр. - С. 1.

47. Церковный вестник Ставропольского благочиния. - 2001. - Окт. (№ 10 (34)). - С. 1-2.

48. Чирков, М. С. Русская церковь в борьбе за сохранение православного наследия (середина 1960-х - начало 1980-х гг.) / М. С. Чирков // Национальное культурное наследие России: региональный аспект : материалы V Всерос. науч.-практ. конф. - Самара : Самар. гос. ин-т культуры, 2017. С. 111-116.

49. Чирков, М. С. Традиционное православие в российском обществе начала XXI века / М. С. Чирков // Традиционные общества: неизвестное прошлое : материалы XV Междунар. науч.-практ. конф. Челябинск : Юж.-Урал. гос. гуманит.-пед. ун-т, 2020. C. 288-295.

50. Шмыгов, А. Плечом к плечу / А. Шмыгов // Презент. - 1996. - 29 нояб. - С. 2. 
51. Шмыгов, А. Противостояние. Что не поделили мусульманские лидеры / А. Шмыгов // Презент центр. $-1998 .-4$ дек. -С. 3.

52. Эпов, Н. Беседа с иеговистской / Н. Эпов // Площадь свободы. - 1991. - 26 нояб. - С. 3.

53. Якунин, В. Н. История православного церковного храмостроительства в Тольятти в 19852000 гг. / В. Н. Якунин // Поволжский вестник науки. - 2020. - № 2 (16). - С. 21-26.

54. Якунин, В.Н.История православного церковного храмостроительства в Тольятти в 2000 2019 гг. / В. Н. Якунин // Поволжский вестник науки. -2020. - № 3 (17). - С. 20-28.

55. Якунин, В. Н. Православная история Ставрополя-Тольятти: источники и литература / В. Н. Якунин // Поволжский вестник науки. - 2020. - № 4 (18). C. $41-45$.

\section{REFERENCES}

1. Analiticheskaya spravka po situatsii v religioznykh organizatsiyakh Tol'yatti za 2003 g. Podgotovlen sotrudnikom merii Tol'yatti Kutyrevoy N. P. [Analytical Report on the Situation in Religious Organizations of Tolyatti for 2003. Prepared by N.P. Kutyreva, Employee of the Tolyatti City Hall]. Arkhiv V.N. Yakunina [Archive of V.N. Yakunin].

2. Batulova S. Blagotvoritel'nost' za chuzhoy schet? [Charity at Someone's Expense?]. Tol 'yattinskoe obozrenie, 2000, March 29, p. 4.

3. Voroncova E. Ya rozhdayus' na zemle snova i snova [I Am Born on the Earth Again and Again]. Ploshchad'svobody, 2000, January 19, p. 3.

4. Gromyko V. Um est' prostranstvo. V Tol'yatti otkryt filial buddijskogo centra Karma-Kag'yu [Mind is Space. A Branch of the Karma Kagyu Buddhist Center Opened in Tolyatti]. Ploshchad'svobody, 1992, July 1, p. 2.

5. Guenko L. Novaya cerkov's privetom iz Cyuriha [New Church with Greetings from Zurich]. Prezent, 1998, March 2, pp. 1-2.

6. Gurevich S. U kazhdogo svoya formula schast'ya [Everyone Has Their Own Formula for Happiness]. Ploshchad'svobody, 1998, October 16, p. 3.

7. El'nikova E. Mormony: Barhatnyj zahvat [Mormons: Velvet Grip]. Politicheskij ring, 1999, December 9, p. 4.

8. Karaulov V., priest. Sekty nastupayut [Sects are Coming]. Lyubimyj gorod, 1996, no. 2, p. 3.

9. Kostin V. Kakuyu zhe «posevnuyu» provodyat u nas krishnaity? [What Kind of "Sowing" is Carried Out by the Krishnaites Here?]. Tol'yatti segodnya, 1995, March 29, p. 3.

10. Lysyakova S. Shatyor chudes v strane durakov [Tent of Wonders in the Land of Fools]. Ploshchad'svobody, 2000, July 27, p. 4.
11. Manihin N. Komu Cerkov' ne mat', tomu Bog ne otec [To Whom the Church is not the Mother, God is not the Father Either]. Ploshchad'svobody, 2000, August 11, p. 4.

12. Moshchenko M. Sekty v zakone. Poka [Sects in the Law. Yet]. Million. Vechernyaya gazeta, 2003, April (no. 7 (66)), p. 3.

13. Moshchenko M. Seti very [Nets of Faith]. Million plyus, 2000, August (no. 80 (210)), p. 3.

14. Otchet arkhiepiskopa Samarskogo i Syzranskogo Sergiya v Moskovskuyu Patriarkhiyu za 1998 g. [Report of Archbishop Sergius of Samara and Syzran to the Moscow Patriarchate for 1998]. Tekushchiy arkhiv Samarskogo eparkhial'nogo upravleniya [Current Archive of the Samara Diocesan Administration], pp. 1-25.

15. Otchet arkhiepiskopa Samarskogo i Syzranskogo Sergiya v Moskovskuyu Patriarkhiyu za $1999 \mathrm{~g}$. [Report of Archbishop Sergius of Samara and Syzran to the Moscow Patriarchate for 1999]. Tekushchiy arkhiv Samarskogo eparkhial'nogo upravleniya [Current Archive of the Samara Diocesan Administration], pp. 1-30.

16. Otchet arkhiepiskopa Samarskogo i Syzranskogo Sergiya v Moskovskuyu Patriarkhiyu za 2001 g. [Report of Archbishop Sergius of Samara and Syzran to the Moscow Patriarchate for 2001]. Tekushchiy arkhiv Samarskogo eparkhial'nogo upravleniya [Current Archive of the Samara Diocesan Administration], pp. 1-35.

17. Panorama Tol'yatti, 2003, January 17, p. 1.

18. Perovskaya S. Pyatidesyatniki «obzhivayut» Central'nyj rajon [Pentecostals "Settle Down" in the Central District]. Ploshchad'svobody, 2000, August 23, p. 4.

19. Pis'mo blagochinnogo Stavropol'skogo okruga protoiereya Nikolaya Manihina v meriyu Tol'yatti zamestitelyu mera g. Tol'yatti S. A. Kaporcevu ot $16.03 .2000 \mathrm{~g}$. [Letter from Archpriest Nikolai Manikhin, Rural Dean of the Stavropol District, to S.A. Kaportsev, Tolyatti City Hall Deputy Mayor of March 16, 2000]. Arkhiv V.N. Yakunina [Archive of V.N. Yakunin].

20. Pis'mo blagochinnogo Stavropol'skogo okruga Samarskoy eparkhii protoiereya Nikolaya Manikhina meru g. Tol'yatti S.F. Zhilkinu ot 14.05.1998 g. [Letter from Archpriest Nikolai Manikhin, Rural Dean of the Stavropol District of the Samara Diocese, to S.F. Zhilkin, Tolyatti City Hall Deputy Mayor of May 14, 1998]. Arkhiv V.N. Yakunina [Archive of V.N. Yakunin].

21. Pis'mo blagochinnogo Stavropol'skogo okruga Samarskoj eparhii protoiereya Nikolaya Manihina predsedatelyu Tol'yattinskoj gorodskoj Dumy Drobotovu A.N. № 38 ot 26.02.1998 [Letter from Archpriest Nikolai Manikhin, Rural Dean of the Stavropol District of the Samara Diocese, to 
A.N. Drobotov, Chairman of the Tolyatti State Duma, No. 38 of February 26, 1998]. Arkhiv V.N. Yakunina [Archive of V.N. Yakunin].

22. Pis'mo direktora departamenta finansov merii g. Tol'yatti V.V. Kushnareva nachal'niku upravleniya po organizacionnym voprosam merii Tol'yatti E.Yu. Oborinoj № 895 ot 01.10 .2001 g. [Letter from V.V. Kushnarev, Director of Finance Department of the Tolyatti City Hall to E.Yu. Oborina, Head of Organizational Affairs Department of the Tolyatti City Hall No. 895 of October 1, 2001]. Arkhiv V.N. Yakunina [Archive of V.N. Yakunin].

23. Pis'mo zamestitelya i. o. nachal'nika glavnogo upravleniya obrazovaniya administracii Samarskoj oblasti V. A. Prudnikovoj № 1818 ot 21.08.2000 g. [Letter from V.A. Prudnikova, Deputy Head of the Main Education Department of Samara Region Administration No. 1818 of August 21, 2000]. Arkhiv V. N. Yakunina [Archive of V.N. Yakunin].

24. Pis'mo zamestitelya ministra obrazovaniya RF E.E. Chepurnykh № 549/28-16 ot 06.07.2000 g. s prilozheniem na $4 \mathrm{~s}$. «Informaciya o deyatel'nosti na territorii Rossii predstavitelej netradicionnyh religioznyh obyedinenij» [Letter from E.E. Chepurnykh, Deputy Minister of Education of the Russian Federation No. 549 / 28-16 of July 6, 2000 with a FourPage Appendix "Information on the Activities of Representatives of Non-Traditional Religious Associations in Russia"]. Arkhiv V.N. Yakunina [Archive of V.N. Yakunin].

25. Ploshchad'svobody, 1997, January 25, p. 1.

26. Ploshchad'svobody, 1999, January 26, p. 1.

27. Povestka dnya vstrechi 22 marta $2000 \mathrm{~g}$. arhiepiskopa Samarskogo i Syzranskogo Sergiya s rukovodstvom g. Tol'yatti, OAO «AVTOVAZ», predprinimatelyami i promyshlennikami Tol'yatti, nastoyatelyami tol'yattinskih prihodov [Agenda of the Meeting on March 22, 2020 of Archbishop Sergius of Samara and Syzran with the Leadership of Tolyatti, OAO “AVTOVAZ”, Entrepreneurs and Industrialists of Tolyatti, Rectors of Tolyatti Parishes]. Arkhiv V.N. Yakunina [Archive of V.N. Yakunin].

28. Polozheniye o konsul'tativnom obshchestvennom sovete po vzaimodeystviyu organov vlasti i religioznykh organizatsiy pri upravlenii po obshchestvennym, mezhregional'nym svyazyam i informatsionno-analiticheskoy rabote merii g. Tol'yatti. Predlozhenija uchastnikov soveta. Povestka zasedanija soveta ot 10.06.2004 g. [Regulations on the Advisory Public Council for Cooperation Between Authorities and Religious Organizations in the Management of Public, Interregional Relations and Information and Analytical Work of Tolyatti City Hall; Suggestions of Council Members; Agenda of the Council Meeting of June 10, 2004]. Arkhiv V.N. Yakunina [Archive of V.N. Yakunin].
29. Postanovlenie mera g. Tol'yatti. 07.08.1998 [Resolution of the Mayor of Tolyatti. August 7, 1998]. Arkhiv V.N. Yakunina [Archive of V.N. Yakunin].

30. Proyekt pis'ma Arkhiyepiskopa Samarskogo i Syzranskogo Sergiya meru Tol'yatti N.D. Utkinu [Draft Letter of Archbishop Sergius of Samara and Syzran to Tolyatti Mayor N.D. Utkin]. Arkhiv V.N. Yakunina [Archive of V.N. Yakunin].

31. Proyekt postanovleniya ob organizatsii Soveta po provedeniyu gosudarstvennoy religiovedcheskoy ekspertizy pri administratsii Samarskoy oblasti [Draft Resolution on Organization of the Council for Conducting State Religious Expert Examination Under the Administration of Samara Oblast]. Arkhiv V.N. Yakunina [Archive of V.N. Yakunin].

32. Proyekt soglasheniya o sotrudnichestve mezhdu meriyey Tol'yattii i Stavropol'skim blagochiniem Samarskoy yeparkhii [Draft Agreement on Cooperation Between Tolyatti City Hall and the Stavropol Deanery of the Samara Diocese]. Arkhiv V.N. Yakunina [Archive of V.N. Yakunin].

33. Protokol № 4 sobraniya Stavropol'skogo blagochiniya ot 16 dekabrya 1999 g. [Protocol No. 4 of the Stavropol Deanery Meeting of December 16, 1999]. Arkhiv V.N. Yakunina [Archive of V.N. Yakunin].

34. Protokol vstrechi v merii Tol'yatti ot 16.09.1999 g. [Protocol of the Meeting in Tolyatti City Hall of September 16, 1999]. Arkhiv V.N. Yakunina [Archive of V.N. Yakunin].

35. Protokol soveshchaniya rabochey gruppy po programme podgotovki k 2000-letiyu Khristianstva [Protocol of the Working Group Meeting on the Preparation Program for the $2000^{\text {th }}$ Anniversary of Christianity]. Arkhiv V.N. Yakunina [Archive of V.N. Yakunin].

36. Protokol zasedaniya Soveta Blagochiniya Stavropol'skogo okruga ot 25.02.1998 [Protocol of the Stavropol District Deanery Council Meeting of February 25, 1998]. Arkhiv V.N. Yakunina [Archive of V.N. Yakunin].

37. Rasporyazhenie mera g. Tol’yatti № $274-1 / \mathrm{r}$ ot 05.07.2001 [Order of the Mayor of Tolyatti No. 274-1/r of July 5, 2001]. Munitsipal'noe kazennoe uchrezhdenie "Tol'yattinskiy arkhiv» [Municipal Public Institution "Tolyatti Archive"], f. R-410, op. 2, d. 546, 1. 42-43.

38. Rasporyazhenie mera g. Tol'yatti № 324-1/r ot 01.08.2001 [Order of the Mayor of Tolyatti No. 324$1 / \mathrm{r}$ of August 1, 2001]. Munitsipal'noe kazennoe uchrezhdenie "Tol'yattinskiy arkhiv» [Municipal Public Institution "Tolyatti Archive"], f. R-410, op. 2, d. 546, 1. 157.

39. Religioznye ob'edineniya grazhdan, zaregistrirovannye v Samarskom oblastnom otdele yusticii [Religious Associations of Citizens Registered in the Samara Regional Department of Justice]. Arkhiv V.N. Yakunina [Archive of V.N. Yakunin]. 
40. Religioznyj sovet gorodu neobhodim. Beseda s imamom-muhtasibom Anasom Galiahmetovichem Galiaskarovym [The City Needs Religious Council. Conversation with Imam-Muhtasib Anas Galiakhmetovich Galiaskarov]. Tol'yatti segodnya, 1997, April 5, p. 3.

41. Reshenie TGD № 738 ot 16.02.2000 g. o meropriyatiyakh, posvyashchennykh prazdnovaniyu 2000-letiya so dnya Rozhdeniya Khristova i Prilozheniye № $1 \mathrm{k}$ nemu [Decision of TGD No. 738 of February 16, 2000 on Events Dedicated to the Celebration of the $2000^{\text {th }}$ Anniversary of the Nativity of Christ and Appendix No. 1 Attached Thereto]. Arkhiv V.N. Yakunina [Archive of V.N. Yakunin].

42. Rusov S. Skandal vokrug stroitel'stva mecheti [Scandal Around the Construction of a Mosque]. Ploshchad'svobody, 1997, October 15, p. 3.

43. Safonova E. Dom Iegovy na stadione «Torpedo» [Jehovah's House at the Torpedo Stadium]. Ploshchad'svobody, 1997, August 9, p. 2.

44. Skoreneva E. Moego muzha uvela sekta [A Sect Took My Husband Away]. Tol'yattinskoe obozrenie, 1999, July 26, p. 3.

45. Tarasova O. Opasno, kogda chelovek stanovitsya fanatikom [It is Dangerous When a Person Becomes a Fanatic]. Ploshchad'svobody, 2001, July 14, p. 2.

46. Tol'yattinskoe obozrenie, 2002, February 15, p. 1.

47. Cerkovnyj vestnik Stavropol'skogo blagochiniya, 2001, October (no. 10 (34)), pp. 1-2.

48. Chirkov M.S. Russkaya tserkov' v bor'be za sokhraneniye pravoslavnogo naslediya (seredina 1960-kh - nachalo 1980-kh gg.) [The Russian Church in the Struggle for the Preservation of the Orthodox Heritage (Mid-1960s - Early 1980s)]. Natsional'noe kul'turnoe nasledie Rossii: regional'nyy aspekt: materialy $V$ Vseros. nauch.-prakt. konf. [National
Cultural Heritage of Russia: Regional Aspect. Proceedings of the $5^{\text {th }}$ All-Russian Scientific and Practical Conference]. Samara, Samarskiy gosudarstvennyy institut kul'tury, 2017, pp. 111-116.

49. Chirkov M.S. Traditsionnoye pravoslaviye v rossiyskom obshchestve nachala XXI veka [Traditional Orthodoxy in Russian Society at the Beginning of the $21^{\text {st }}$ Century]. Traditsionnye obshchestva: neizvestnoe proshloe: materialy XV Mezhdunar. nauch.-prakt. konf. [Traditional Societies: An Unknown Past. Proceedings of the $15^{\text {th }}$ International Scientific and Practical Conference]. Chelyabinsk, Yuzhno-Ural'skiy gosudarstvennyy gumanitarno-pedagogicheskiy universitet, 2020, pp. 288-295.

50. Shmygov A. Plechom k plechu [Shoulder to Shoulder]. Prezent, 1996, November 29, p. 2.

51. Shmygov A. Protivostoyanie. Chto ne podelili musul'manskie lidery [Confrontation. What Did Muslim Leaders Fail to Share]. Prezent centr, 1998, December 4, p. 3.

52. Epov N. Beseda s iegovistskoj [Conversation with Jehovah's Witness]. Ploshchad'svobody, 1991, November 26, p. 3.

53. Yakunin V.N. Istoriya pravoslavnogo cerkovnogo xramostroitel'stva v Tol'yattiv 1985-2000 gg. [The History ofOrthodox Church Building in Tolyatti in 1985-2000]. Povolzhskij vestnik nauki [Volga Bulletin of Science], 2020, no. 2 (16), pp. 21-26.

54. Yakunin V.N. Istoriya pravoslavnogo cerkovnogo xramostroitel'stva v Tol'yatti v2000-2019 gg. [The History of Orthodox Church Building in Tolyatti in 2000-2019]. Povolzhskij vestnik nauki [Volga Bulletin of Science], 2020, no. 3 (17), pp. 20-28.

55. Yakunin V.N. Pravoslavnaya istoriya Stavropolya-Tol'yatti: istochniki i literatura [Orthodox History of Stavropol-Tolyatti: Sources and Literature]. Povolzhskij vestnik nauki [Volga Bulletin of Science], 2020, no. 4 (18), pp. 41-45.

\section{Information About the Author}

Vadim N. Yakunin, Doctorof Sciences (History), Professor, Department of Theology, Philosophy and History, Volga State Orthodox Institute, Yubileynaya St, 4a, 445024 Tolyatti, Russian Federation, vadyak@mail.ru,https://orcid.org/0000-0002-0464-2938

\section{Информация об авторе}

Вадим Николаевич Якунин, доктор исторических наук, профессор кафедры теологии, философии и истории, Поволжский православный институт им. Святителя Алексия, митрополита Московского, ул. Юбилейная, 4a, 445024 г. Тольятти, Российская Федерация, vadyak@mail.ru, https://orcid.org/0000-0002-0464-2938 